\title{
Mode of Delivery and Labour Analgesia: A Study of Preference in Portuguese Pregnant Women
}

Inês Coelho da Costa ${ }^{1}$, Catarina S. Nunes ${ }^{2,3,4}$ and Humberto S Machado ${ }^{1,2,3^{*}}$

${ }^{1}$ Instituto de Ciências Biomédicas Abel Salazar, Universidade do Porto, Porto, Portugal

${ }^{2}$ Serviço de Anestesiologia, Centro Hospitalar do Porto, Porto, Portugal

${ }^{3}$ Centro de Investigação Clínica em Anestesiologia, Centro Hospitalar do Porto, Porto, Portugal

${ }^{4}$ Departamento de Ciências e Tecnologia, Universidade Aberta, Delegação do Porto, Rua do Amial 752, $4200-055$ Porto, Portugal

*Corresponding author: Humberto S Machado, Centro de Investigação Clínica em Anestesiologia, Centro Hospitalar do Porto, Porto, Portugal, Tel: +351-935848475; E-mail: hjs.machado@gmail.com

Received date: May 24, 2018; Accepted date: July 30, 2018; Published date: August 03, 2018

Copyright: $@ 2018$ Costa IC, et al. This is an open-access article distributed under the terms of the Creative Commons Attribution License, which permits unrestricted use, distribution, and reproduction in any medium, provided the original author and source are credited.

\begin{abstract}
Background: Portugal has had one of the highest cesarean rates in Europe, possibly influenced by patient preferences. A reduction in the prevalence of these rates due to safety, quality, and concern with costs is one of the current goals of obstetric care. Fear of pain, often associated with vaginal delivery, is one of the reasons why pregnant women might prefer a cesarean section.
\end{abstract}

Objective: The aim of this study was to identify the type of delivery and anaesthesia/analgesia preferred, as well as the reasons and factors associated with this preference, in a representative sample in order to identify possible modifiable factors possibly involved in increased rates.

Methods: A descriptive cross-sectional study was carried out by an anonymous questionnaire to 245 pregnant women from February to April 2018. Respondents were also asked about their preference for peripartum anaesthesia/analgesia and on the sources of information that helped decide their preferences.

Results: $22 \%$ of respondents would prefer an elective cesarean section. This preference was higher in women with a previous cesarean section. The preference for vaginal delivery was higher in women with more advanced pregnancies. The main reasons that led participants to prefer a vaginal delivery were the quicker postpartum recovery and not wanting to miss the first hours of their child's life. Regarding the preference for an elective cesarean section, the main reasons were fear and convenience. Most pregnant women preferred epidural analgesia. Respondents who selected their doctor (most common source) were more likely to prefer vaginal delivery.

Conclusion: A minority of women showed a preference for cesarean delivery. A majority would prefer to have epidural anaesthesia. Despite the high cesarean rates, maternal desire for cesarean section is low, suggesting that this number is due to factors other than the preference of pregnant women.

Keywords: Cesarean section; Pregnant woman; Obstetrical analgesia; Patient preference; Cross-sectional studies; Surveys; Questionnaires

\section{Introduction}

Cesarean section (CS) was introduced into clinical practice as a lifesaving procedure for both mother and baby [1]. However, it is a surgical approach and as such, carries additional risks when compared to vaginal delivery (VD). Studies have shown that cesarean deliveries carry substantially higher morbidity rates, risk of cardiac arrest, wound hematoma, hysterectomy, major infection and anaesthetic complications [2,3] as well as a higher risk of major bleeding compared to vaginal birth [3]. For the infant, in cases of cephalic presentation, it is also associated with increased mortality [4] as well as a seven-fold higher risk of respiratory morbidity [5].

CS rate is indicated by the World Health Organization (WHO) as one of the main indicators of maternal and reproductive health [6]. In 1985 WHO stated that "there is no justification to have a cesarean section rate of higher than $10 \%-15 \% "$ [7]. In 2015, through a statement on cesarean section rates, WHO said it did not recommend a specific rate since needs for this type of delivery vary dramatically among hospitals, depending on the population served. This note ended by saying that instead of setting a setting a specific target rate, efforts should be concerned with ensuring that the procedure is provided to women in need [8].

In recent decades, there has been an unprecedented and constant rise in the rates of cesarean delivery, which has led to an increase in research, debate, and concern among health professionals and policy makers [9]. Approximately 20 million cesarean sections are performed annually worldwide, making this the most common abdominal surgery performed in adults [10]. Since 2000, the percentage of cesarean sections has been increasing in most Organization for Economic Cooperation and Development (OECD) member countries, with the average increasing from $20 \%$ in 2002 to $28 \%$ in 2017 [11]. It has been proven that CS rates of above $10 \%$, is not associated with reductions in 
maternal and neonatal mortality rates and therefore may not be necessary to achieve lower maternal and neonatal mortality [12].

In Portugal, there is a record of a $3 \%$ annual increase in cesarean rates up to 2013 [13]. In fact, from 2009 to 2013 , this was the $5^{\text {th }}$ OECD member country with the highest percentages of cesarean deliveries ranging from $27.0 \%$ in 2009 to $34.8 \%$ in 2013 [14]. Recently there has been a reversal of this trend. According to the most recent data, Portugal has dropped to the $10^{\text {th }}$ position, with $32 \%$ [15]. This can be, in part, due to the implementation of a set of measures by the Portuguese National Health Service, following the establishment of the National Commission for the Reduction of Cesarean Rates in 2013. Since the creation of this commission, there has been a $2.8 \%$ reduction in cesarean deliveries nationwide [15]. However, if rates between publicly and privately-run hospitals are compared it is clear that this reduction is largely due to the former. Between 2013 and 2016, the percentage of cesarean sections in public hospitals decreased by $3 \%$ [16] while in private hospitals this decrease was $0.5 \%$ [17].

Currently, the rate of cesarean sections in Portuguese private hospitals is $65.5 \%$ [17], more than double that of state-run hospitals (27.6\%) [16]. The different CS rates seen in public and private hospitals may suggest that both the differences between patient preference for delivery mode and differences in the organization of antenatal and intrapartum care in these two entities may have an impact on the modality of labour $[18,19]$. Albeit, it is unclear whether there is, in fact, a difference in preference between pregnant women in both sectors. Mazzoni et al. surveyed women in public and private hospitals in Buenos Aires, Argentina, and found that preferences for the type of delivery were similar in both sectors: of all healthy and nulliparous women interviewed, only $8 \%$ in the public sector and $6 \%$ in the private sector, expressed preference for elective caesarean section [20].

In the Portuguese National Health Service, cesarean sections should only be performed when medically indicated and not based on a maternal request or the physician's convenience. In 2015, in order to increase scrutiny of the country's obstetrical and neonatal services, the Directorate-General for Health issued a standard stating that all hospitals with intrapartum obstetrical care (public and private) should have a register of CS indications for each woman performing this procedure and should also make their data available for internal and external audits whenever requested. The reasons listed included any maternal pathology that contraindicates natural childbirth, a fetal anomaly that contraindicates vaginal delivery, pregnancy-related conditions, prior uterine surgery, abnormal fetal status or presentation, multiple pregnancy (triple pregnancy, twin pregnancy with first fetus in pelvic presentation), suspected fetal-pelvic incompatibility, failed attempt to induce labor, stationary labor and non-reassuring fetal status [21].

The reasons for the increase in cesarean delivery rates are multifactorial and not yet well understood. These include the increasing number of multiple pregnancies as a result of medically assisted reproduction, concerns about medical liability and malpractice, convenience in scheduling the date and time of delivery for both the physician and the mother and the increase in preference of some women for this mode of delivery [15]. Although patient demanded cesareans are one of the most frequently cited reasons [22-24] and some studies suggesting that elective cesareans due to maternal preference are a relevant factor for the increase in cesarean rates $[25,26]$ there is evidence that most women, in many parts of the world, would rather have a vaginal delivery [27]. Nevertheless, the importance of this factor is justified by the greater attention given to patient-doctor communication and patient participation [28], which can sometimes mean that women who express a preference for a cesarean section can have a surgical birth instead of a vaginal delivery without clear medical indication [29]. In fact, it has already been demonstrated that a significant number of obstetricians would agree to perform an elective cesarean, even without medical indication, at the request of the mother [30-33].

Fear of pain often associated with vaginal delivery is commonly pointed out as one of the reasons why pregnant women prefer cesarean delivery $[10,20,34]$. The pain experienced by women during childbirth is variable and is sometimes described as one of the worst possible pains [35]. There are a number of non-pharmacological (such as water delivery, relaxation, acupuncture) and pharmacological alternatives (such as sedatives, epidural, local anaesthesia for nerve block) for pain relief. Pregnant women are free to choose any type of analgesia, after being advised by their doctors on the benefits and possible adverse effects for them and the baby [36]. However, childbirth is a multidimensional experience and when analgesia is considered, the goals of pain relief with other physical, emotional, psychological, sociological and sometimes religious considerations should be equated [37]. In other words, pain relief may not be enough to make delivery a positive and satisfactory experience. Increasing numbers of women have been using epidural as a strategy to control pain during childbirth [38], even though it is associated with an increased risk of instrumented birth [39].

Although, historically, Portugal has always had one of the highest cesarean rates, no study that attempted to understand the preference of Portuguese pregnant women regarding delivery mode was found. This was the motivation behind this study. By collecting the opinions of a representative sample of women, we can better understand their wishes and identify possible modifiable factors eventually behind the increased rates. The aim of this study was to identify the type of delivery and anaesthesia preferred, as well as the reasons and factors associated with these preferences, in a representative sample of Portuguese pregnant women.

\section{Methods}

\section{Study area and design}

In order to study the preference for mode of delivery, a descriptive cross-sectional study was carried out by distributing questionnaires to pregnant women at the Centro Matero-Infantil do Norte (CMIN) the maternal and child health center of the Centro Hospitalar do Porto (CHP), the central hospital of Porto, in the city of Porto, between February and April 2018. The questionnaire was distributed in person, in the waiting rooms of CMIN's outpatient clinic to pregnant women who were there for their pregnancy follow-up. The study population included all pregnant women who were available to complete the survey regardless of their gestational age or obstetric history.

The CHP's Gynecology and Obstetrics department has a large area of influence, including the greater metropolitan area of Porto, with the exception of some municipalities. It also receives patients from neighbouring municipalities and from the entire north of Portugal. CMIN is the hospital unit with the highest number of births (in absolute number) in the northern region of Portugal, the second largest in the country. It is the largest maternity hospital at a national level (in the absolute number of births and in the number of obstetricsgynaecology medical specialists in the region, as well as in the number 
of consultations and surgeries in the country) [40]. In 2016 this unit performed 902 cesarean sections and a total of 3,234 deliveries. The gross cesarean rate of $27.9 \%$ is due to the fact that CHP is a reference centre for at-risk pregnancies $(59.5 \%$ of deliveries result from high-risk pregnancies). If we consider the risk-adjusted cesarean rate (RACR), the values are lower and follow a decreasing trend [41].

\section{Sample size}

The sample size was determined by taking into account the incidence of cesarean delivery preference reported in the meta-analysis Mazzoni et al. [27], of 15.6\%, and the number of births in Portugal in 2016 of 86,254 (Source: National Institute of Statistics, IP-Portugal) [42]. A margin of error of $5 \%$ and a confidence level of $95 \%$ was used. A minimum sample size of 202 questionnaires (StatsDirect ${ }^{\circledR}$ ) was obtained. Predicting a margin of non-response/loss of 20\%, 245 questionnaires were considered as the final sample size.

\section{Survey instrument}

The survey instrument (Appendix 1) took about 3 min to complete. It was divided into three sections. The first section assessed preference for delivery type and included a closed-ended question about the preferred type of delivery, in which the two possible responses were 'Vaginal delivery' or 'Caesarean section'. Depending on their choice, respondents were directed to one of two sub-sections, exploring the reasons for their preference as well as their choices concerning anaesthesia. In regard to the reasons for preference of each birth mode, sub-sections were composed of ten statements and the responses were measured using a 5-point Likert scale, in which 1 meant "strongly disagree" and 5 "strongly agree". There was also the possibility of selecting the answer "I don't know" and adding, in the end, other reasons in an open-ended format. The desire for anesthesia/analgesia was determined by the question "Would you opt for analgesia?" in women who preferred vaginal delivery (where the possible responses were "Yes, epidural analgesia", "Yes, local analgesia", "No" and "I don’t know"), and "What kind of anesthesia would you prefer?" in women who preferred cesarean delivery (where the options were "epidural anesthesia", "local anesthesia", "general anesthesia" and "I don't know").

The second section questioned participants on how they obtained the information that influenced their choice, offering the possibility of selecting from eight possible sources (such as the internet, general practitioner $\{\mathrm{GP}\} /$ obstetrician, and family members), as well as the possibility of adding different reasons in an open-ended format or opt for "I haven't thought about it".

The third and last section collected information on the sociodemographic characteristics of respondents (such as age and education), as well as obstetric history (gestational age, parity, and previous cesarean sections).

After conducting a literary review, it was possible to identify a questionnaire used in the study by Torloni et al. [10] on the preference for CS in a sample of Italian women, which served as a base for the elaboration of the survey instrument used in this study. The original questionnaire, developed by a team of researchers with experience in the field of public health and surveys, was initially tested on ten volunteers and modified to ensure that all questions were clear and unambiguous. Questions that were systematically unanswered were also changed. The final version was tested once more to ensure face and content validity. Some changes were made to this original document and a final version was developed in order to better meet the purpose of the study and to be in line with the Portuguese reality. These changes included the alteration of some of the statements in the sub-section exploring the reasons for preference that ensured a smaller disparity between the options presented for each type of delivery as well as the addition of a question on the preference of pregnant women for peripartum anaesthesia/analgesia.

\section{Data analysis}

The statistical analysis was conducted using the Statistical Package for Social Sciences, SPSS, version 25 (SPSS, Inc., Chicago, USA). Descriptive statistics were used to analyze the sociodemographic characteristics of the study population, the obstetric history, the information sources and the mode of delivery preferred. The chisquare test was used to compare differences between categorical variables such as the type of delivery and level of education, parity, previous cesarean section and source of information $(\mathrm{p}<0.05$ was considered significant). A t-test of independent samples was conducted to compare the means of age and the gestational age with the preferred delivery type.

\section{Ethical consideration}

The study was approved by the board of directors of CHP having been previously analyzed by the Ethics Committee for Health, the CHP's Research Coordinating Office of the Department of Education, Training and Research (Departamento de Ensino, Formação e Investigação - DEFI) and by the President of the board of directors having obtained a favourable report. In the questionnaire cover page, the purpose of the study was explained to participants as well as the fact that their participation was voluntary and anonymous.

\section{Results}

The statistical analysis included 245 pregnant women who completed the questionnaire. In one of the questionnaires, no option was selected for the first question "If you could choose, what delivery type would you prefer?" and in another, the fields that questioned about sociodemographic characteristics were not filled. Nevertheless, these questionnaires were included for analysis of the remaining sections.

\section{Sociodemographic characteristics of the sample}

The mean age of respondents was $31.7( \pm 5.3)$ years and the mean gestational age was $25.1( \pm 8.6)$ weeks. About $35 \%$ of the participants had a university degree and $32 \%$ had completed their secondary education. More than half of the women (57.8\%) had had at least one previous delivery and of these, approximately $40 \%$ had a prior CS. The sociodemographic characteristics and obstetric history are shown in (Table 1).

\section{Respondents preference for delivery mode}

$77.9 \%$ of the respondents said that, if they could choose, they would prefer vaginal delivery (22.1\% would prefer cesarean section) (Figure $1)$.

\section{Factors influencing the preferred type of delivery}

There was a significant difference in the gestational ages of women who preferred vaginal delivery and those who preferred an elective 
Citation: Costa IC, Nunes CS, Machado HS (2018) Mode of Delivery and Labour Analgesia: A Study of Preference in Portuguese Pregnant Women. J Anesth Clin Res 9: 849. doi:10.4172/2155-6148.1000849

Page 4 of 11

cesarean. Women with a cesarean preference had on average a gestational age of 23 weeks and women who preferred vaginal delivery were, on average, on their $26^{\text {th }}$ week $(\mathrm{p}<0.05)$. It was not possible to demonstrate a statistically significant association between maternal age and the preferred delivery type (Table 2).

\begin{tabular}{|l|l|}
\hline Variable & Mean \pm SD, $\mathbf{n}$ (\%) \\
\hline Age (years) & $31.7 \pm 5.3$ \\
\hline Gestacional age (weeks) & $25.1 \pm 8.6$ \\
\hline Education & $12(4.9 \%)$ \\
\hline Didn't complete primary school & $26(10.7 \%)$ \\
\hline Completed primary school & $77(31.6 \%)$ \\
\hline Completed secondary school & $86(35.2 \%)$ \\
\hline Bachelor's & $43(17.6 \%)$ \\
\hline $\begin{array}{l}\text { Degree higher than bachelor's (Masters, doctoral } \\
\text { degree) }\end{array}$ & $141(57.8 \%)$ \\
\hline Previous labour & $103(42.2 \%)$ \\
\hline Yes & $42(40.8 \%)$ \\
\hline No & \multicolumn{2}{|l}{} \\
\hline Within previous labour & \\
\hline At least one previous CS & \\
\hline
\end{tabular}

No previous CS

$61(59.2 \%)$

Table 1: Sociodemographic characteristics and obstetric history of respondents. SD: Standard Deviation; n: Number; CS: Cesarean Section.

Among the group of women who preferred CS and had had a previous delivery, about $73 \%$ had already had at least one C-section. Within the multiparous women with a preference for vaginal delivery, $31.3 \%$ had had a cesarean section $(\mathrm{p}<0.05)$ (Figure 2$)$.

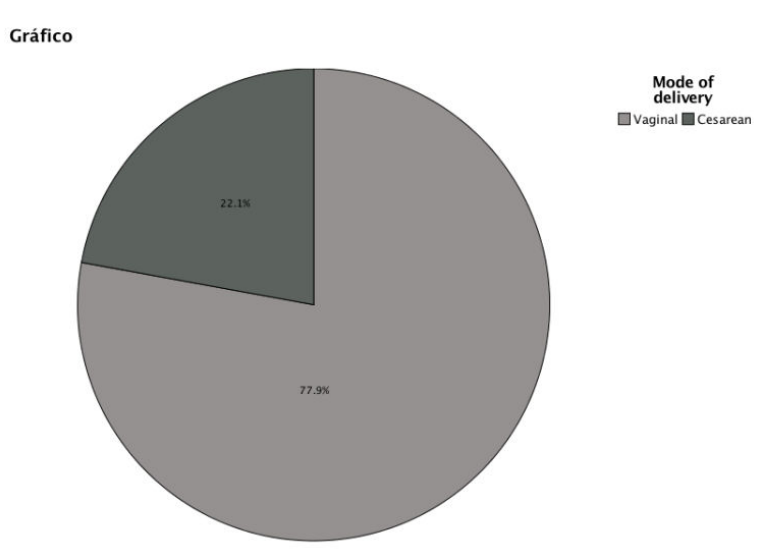

Figure 1: Mode of delivery preferred by Portuguese pregnant women $(n=244)$.

\begin{tabular}{|c|c|c|c|c|c|c|c|}
\hline & $\begin{array}{l}\text { Preferred mode } \\
\text { of delivery }\end{array}$ & Mean \pm SD Standard error & \multicolumn{2}{|c|}{$\begin{array}{l}\text { Levene's Test for } \\
\text { Equality of Variances }\end{array}$} & \multicolumn{3}{|c|}{ T-test for equality of means } \\
\hline & & & $\mathrm{F}$ & Sig. & $\mathrm{t}$ & df & Sig. (2-tailed) \\
\hline \multirow{4}{*}{ Maternal age } & \multirow[t]{2}{*}{ Vaginal } & 31.31 years \pm 5.362 & \multirow[t]{4}{*}{0.277} & \multirow[t]{4}{*}{0.599} & \multirow[t]{4}{*}{2.06} & \multirow[t]{4}{*}{240} & \multirow[t]{4}{*}{0.040} \\
\hline & & 0.390 & & & & & \\
\hline & \multirow[t]{2}{*}{ Cesarean } & 32.81 years \pm 5.025 & & & & & \\
\hline & & 0.684 & & & & & \\
\hline \multirow[t]{4}{*}{ Gestational age } & \multirow[t]{2}{*}{ Vaginal } & 25.76 weeks \pm 8.547 & \multirow[t]{4}{*}{0.512} & \multirow[t]{4}{*}{0.475} & \multirow[t]{4}{*}{-1.848} & \multirow[t]{4}{*}{241} & \multirow[t]{4}{*}{0.066} \\
\hline & & 0.622 & & & & & \\
\hline & \multirow[t]{2}{*}{ Cesarean } & 23.02 weeks \pm 8.554 & & & & & \\
\hline & & 1.175 & & & & & \\
\hline
\end{tabular}

Table 2: T-test: Relationship between the preferred delivery mode, gestational age and maternal age. SD: Standard Deviation; Sig: Significance level; df: degrees of freedom.

There was no significant relationship between educational level and preference for delivery mode, with the majority preferring vaginal delivery regardless of their education (Table 3 ).

\section{Reasons for vaginal delivery preference}

$75 \%$ to $80 \%$ of women interviewed strongly agreed or agreed with preferring a vaginal delivery due to the shorter hospital stay, not wanting to lose the first hours of life of their child and having faster postpartum recovery (Figure 3). A smaller number of respondents $(60.7 \%)$ said they strongly agreed or agreed with the statement that they preferred a vaginal delivery because they knew more people who had had a vaginal delivery and less than half (47.7\%) strongly agreed or agreed that leaving no scar would be a reason for preferring this mode. 


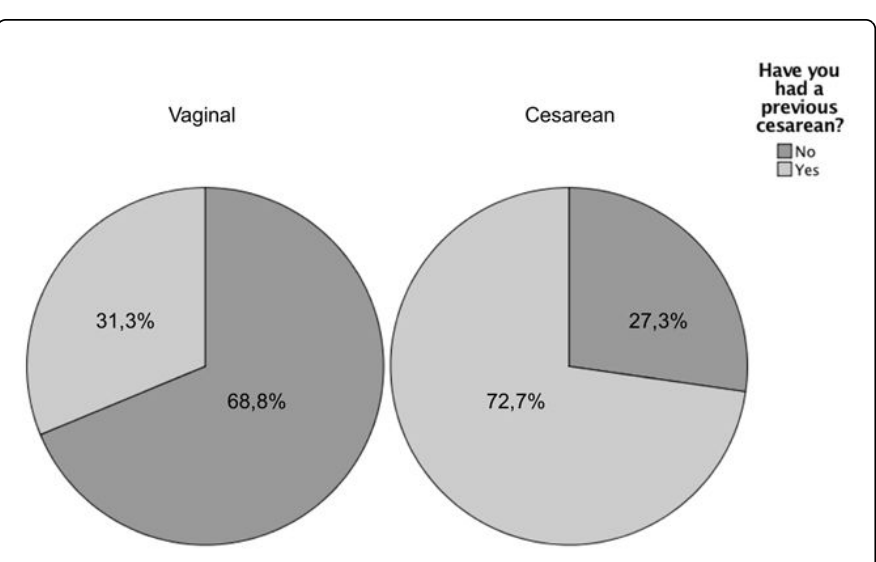

Figure 2: Preferred mode of delivery within women with previous cesarean. Section $(\mathrm{n}=92)$; $\mathrm{n}$ : number of women.
Regarding the motives which saw the largest number of women in disagreement, $52.1 \%$ of the women said they did not agree that having a previous cesarean section influenced them to choose a vaginal delivery and $46.2 \%$ said that it was not the fear that led them to choose this route (Tables 4 and 5).

Still, in the group of women who preferred vaginal delivery, the statements that presented a smaller interquartile range (equal to 1) were faster postpartum recovery, shorter hospital stay and not wanting to lose the first hour of their child's life (Table 6 and Figure 4). The reasons with greater response dispersion were the absence of scar (interquartile range $=3$ ) and rejecting a surgical intervention (interquartile range $=4$ ).

Other reasons cited by the respondents in the open-ended form were the fact that it is the most "natural" method (reported by 6 women) and the fact that this mode is beneficial to the newborn (referred by 4 ).

\begin{tabular}{|c|c|c|c|c|c|c|c|}
\hline & & $\begin{array}{l}\text { Didn't } \\
\text { complete } \\
\text { primary school }\end{array}$ & $\begin{array}{l}\text { Completed } \\
\text { primary school }\end{array}$ & $\begin{array}{l}\text { Completed } \\
\text { secondary school }\end{array}$ & Bachelor's & $\begin{array}{l}\text { Degree higher } \\
\text { than bachelor's } \\
\text { (Master's, } \\
\text { Doctoral degree) }\end{array}$ & Total \\
\hline \multirow{4}{*}{$\begin{array}{l}\text { Preferred mode of } \\
\text { delivery }\end{array}$} & Vaginal (n) & 11 & 22 & 54 & 70 & 32 & 189 \\
\hline & $\mathrm{n}(\%)$ & $91.70 \%$ & $84.60 \%$ & $70.10 \%$ & $82.40 \%$ & $74.40 \%$ & $77.80 \%$ \\
\hline & Cesarean (n) & 1 & 4 & 23 & 15 & 11 & 54 \\
\hline & $\mathrm{n}(\%)$ & $8.30 \%$ & $15.40 \%$ & $29.90 \%$ & $17.60 \%$ & $25.60 \%$ & $22.20 \%$ \\
\hline \multirow[t]{2}{*}{ Total } & $\mathrm{n}$ & 12 & 26 & 77 & 85 & 43 & $243^{1}$ \\
\hline & $\mathrm{n}(\%)$ & $4.90 \%$ & $10.70 \%$ & $31.70 \%$ & $35.00 \%$ & $17.70 \%$ & \\
\hline & & & & Value & df & \multicolumn{2}{|c|}{ Asymptotic Significance (2-sided) } \\
\hline \multicolumn{4}{|c|}{ Pearson Chi-Square } & $5.958^{\mathrm{a}}$ & 4 & \multicolumn{2}{|l|}{0.202} \\
\hline
\end{tabular}

Table 3: Relationship between education level and preferred mode of delivery; Pearson Chi-Square tests. n: number of women; df: degrees of freedom. ${ }^{1}$ Two questionnaires were excluded from this analysis for incorrect completion of section 3 .

\section{Reasons for elective cesarean preference}

In the group of respondents who preferred cesarean delivery (Figure 5), fear in general, fear of pain, and the possibility of scheduling the date and time of birth was something that roughly $60 \%$ strongly agreed or agreed with. Approximately $50 \%$ of women said they strongly agreed or agreed that less suffering for the baby and increased safety for the mother were reasons for preferring this rout. While $28 \%$ of women said they agreed that a faster return to their sex life would be a reason for their preference, $36 \%$ said they did not know the impact of this statement on their choice. This was the statement with most women saying, "I don't know". Only $1.9 \%$ of the women said that they did not agree that having had a previous cesarean section influenced them to choose a vaginal delivery.

Figure 6 and Table 7 show that the statements that presented less dispersion in the strength of agreement/disagreement among those surveyed with a cesarean preference were fear of pain and the possibility of programming delivery (interquartile range $=2$ ), with which the majority was in agreement.

It was also mentioned by three women that the fact that they were conditioned by medical reasons (retinal detachment, endometriosis and scar revision from a previous cesarean) was what lead to their preference for a cesarean.

\section{Respondents preference for analgesia}

Regarding the questions that assessed the preference for analgesia, in the group of women who preferred to delivery vaginally, there was a greater preference for epidural analgesia $(73.89 \%)$, and about $8 \%$ said they did not want any form of pain relief (Figure 7). There was no statistically significant relationship between preference for anaesthesia type and the source of information, gestational age, educational level, age and previous labour experiences. 
Citation: Costa IC, Nunes CS, Machado HS (2018) Mode of Delivery and Labour Analgesia: A Study of Preference in Portuguese Pregnant Women. J Anesth Clin Res 9: 849. doi:10.4172/2155-6148.1000849

Page 6 of 11

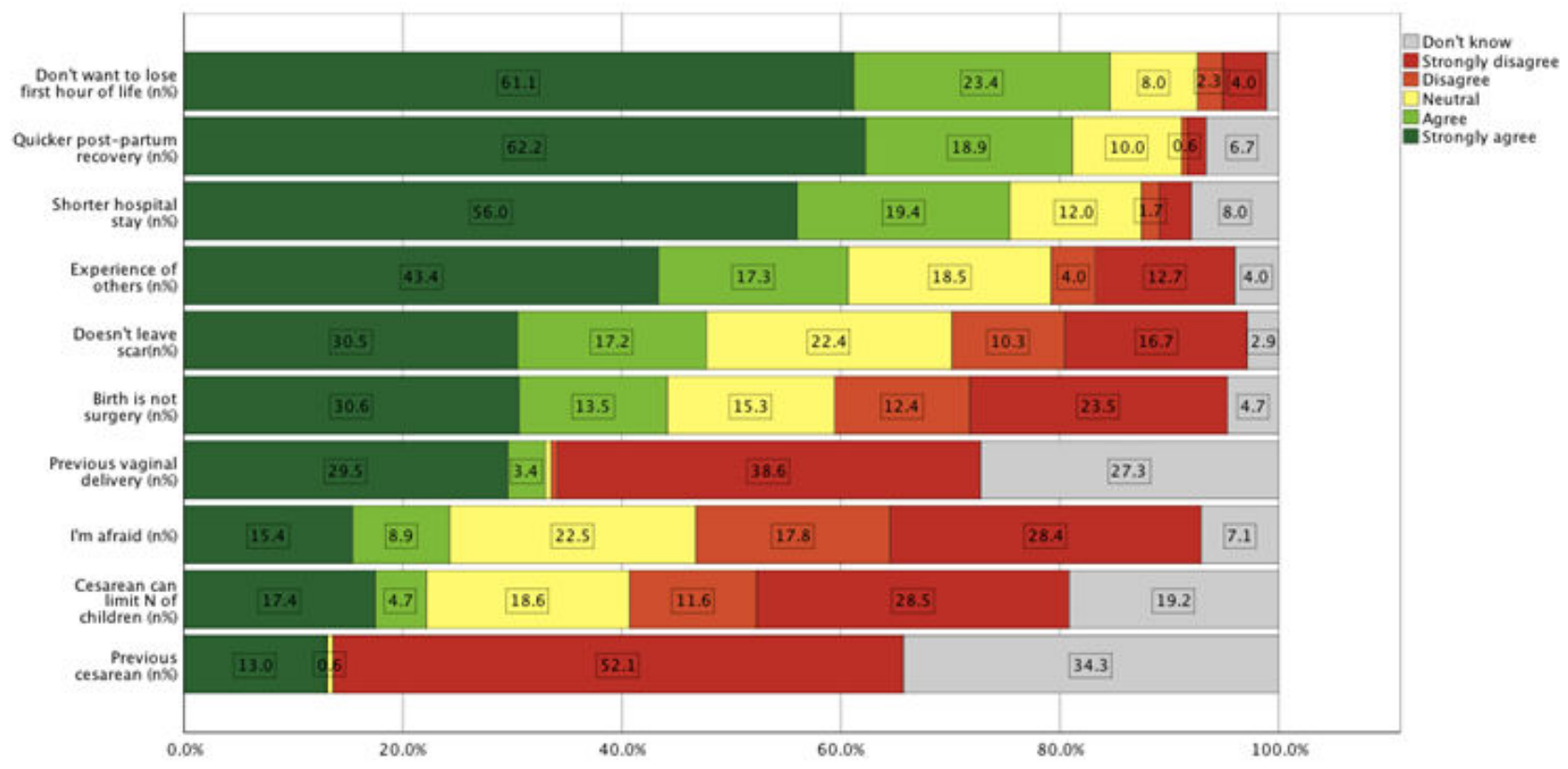

Figure 3: Main reasons for preferring vaginal birth $(n=190)$. $n$ : number.

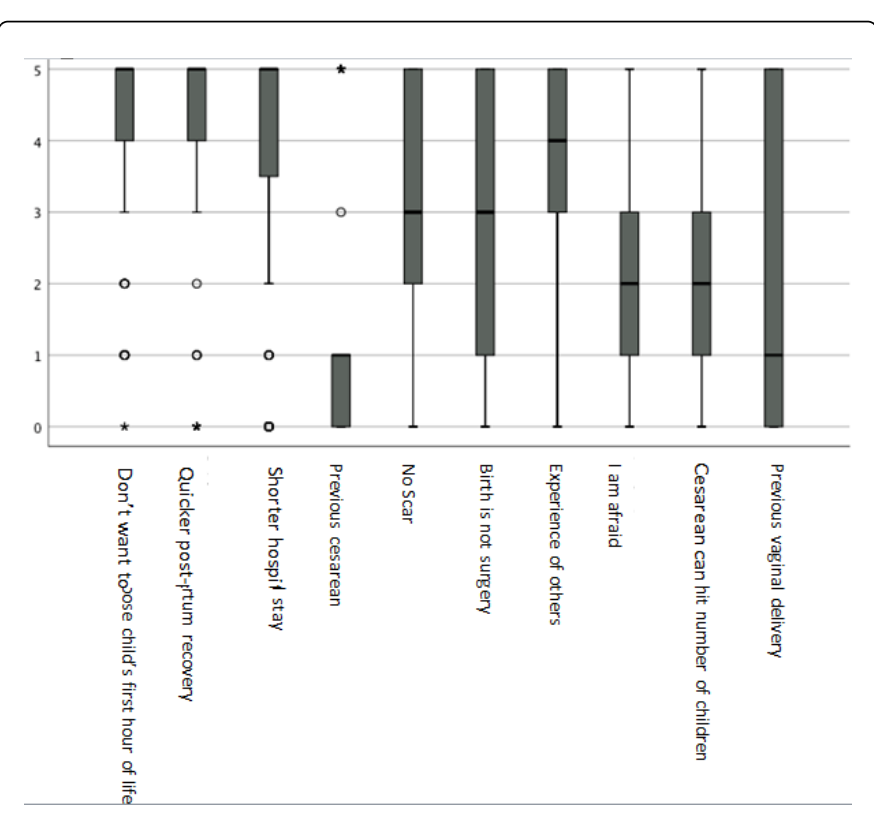

Figure 4: Boxplot: Reasons for preferring vaginal delivery.

Similarly, among the group of women who preferred cesarean section, results showed that the majority preferred to have an epidural analgesia (56.69\%); $18.8 \%$ said they did not know which method of pain relief they would prefer (Figure 8). Also in this group, there was no statistically significant relationship between preference for the type of anaesthesia and the source of information, gestational age, educational level, age and previous labour experiences.

\begin{tabular}{|l|l|l|l|l|}
\hline Source & $\mathbf{n}(\%)$ & \multicolumn{3}{l|}{ Pearson Chi-Square Test } \\
\hline & & Value & $\mathbf{d f}$ & \multicolumn{1}{|l|}{$\begin{array}{l}\text { Asymptotic } \\
\text { Significance } \\
\text { (2-sided) }\end{array}$} \\
\hline $\begin{array}{l}\text { Through my obstetrician/ } \\
\text { attending doctor }\end{array}$ & $107(44.1 \%)$ & $4.310^{\mathrm{a}}$ & 1 & 0.038 \\
\hline Through a family member & $68(27.8 \%)$ & $3.016^{\mathrm{a}}$ & 1 & 0.082 \\
\hline Through a friend & $54(22.0 \%)$ & $2.154^{\mathrm{a}}$ & 1 & 0.142 \\
\hline Through the Internet & $44(18.0 \%)$ & $.486^{\mathrm{a}}$ & 1 & 0.486 \\
\hline Through a course/books & $42(17.1 \%)$ & $.015^{\mathrm{a}}$ & 1 & 0.904 \\
\hline Through my husband/partner & $32(13.1 \%)$ & $1.982^{\mathrm{a}}$ & 1 & 0.159 \\
\hline I haven't thought about it & $39(15.9 \%)$ & $2.010^{\mathrm{a}}$ & 1 & 0.156 \\
\hline $\begin{array}{l}\text { Through newspapers/ } \\
\text { magazines }\end{array}$ & $19(7.8 \%)$ & $.481^{\mathrm{a}}$ & 1 & 0.488 \\
\hline Through television & $17(6.9 \%)$ & $1.139^{\mathrm{a}}$ & 1 & 0.286 \\
\hline
\end{tabular}

Table 4: Source of information that helped respondents decide their preferred mode of delivery; Pearson Chi-Square Test. n: number of women; df: degrees of freedom. 


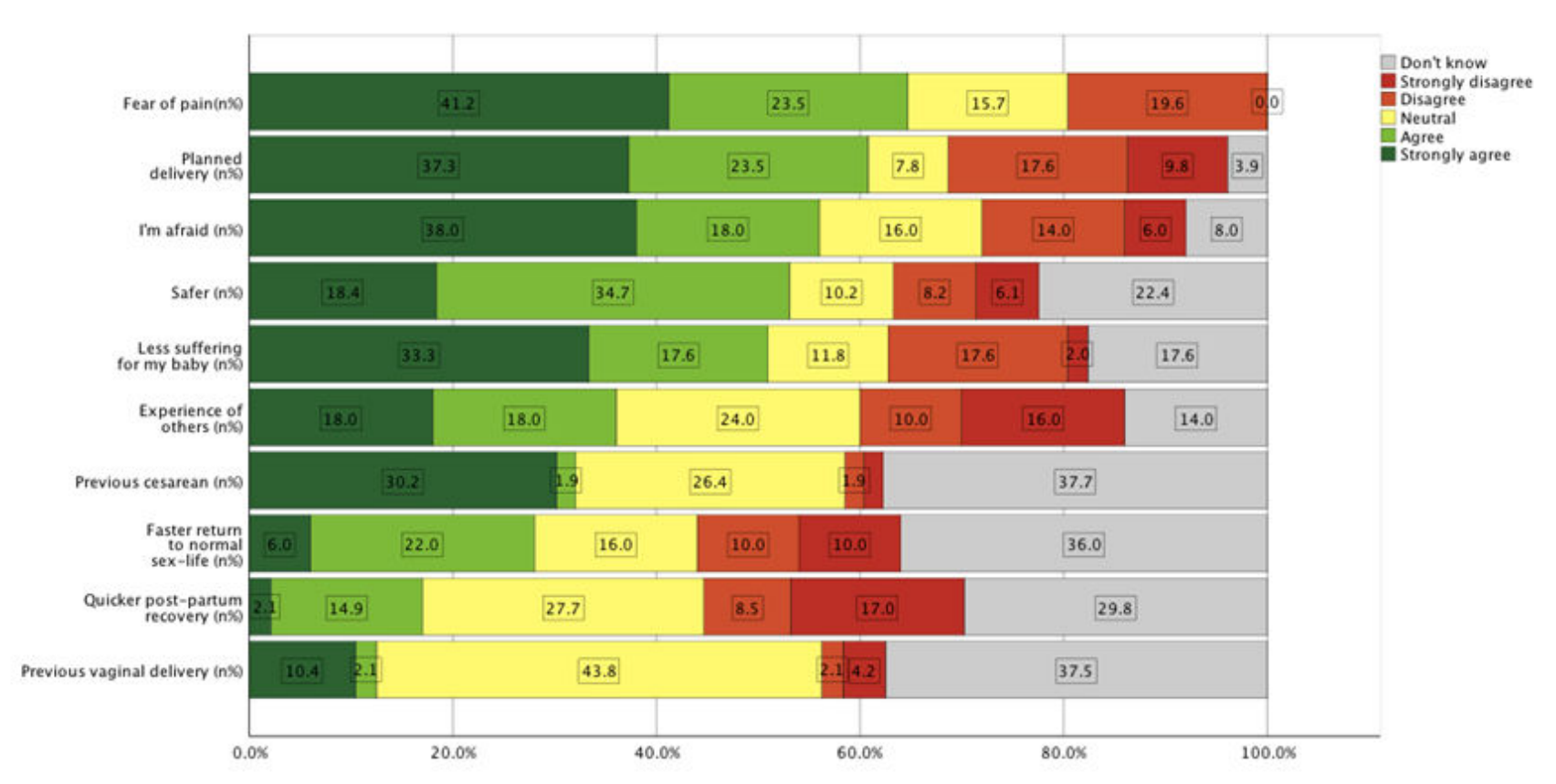

Figure 5: Main reasons for preferring CS ( $\mathrm{n}=55)$. CS: Cesarean Section; $\mathrm{n}$ : number.

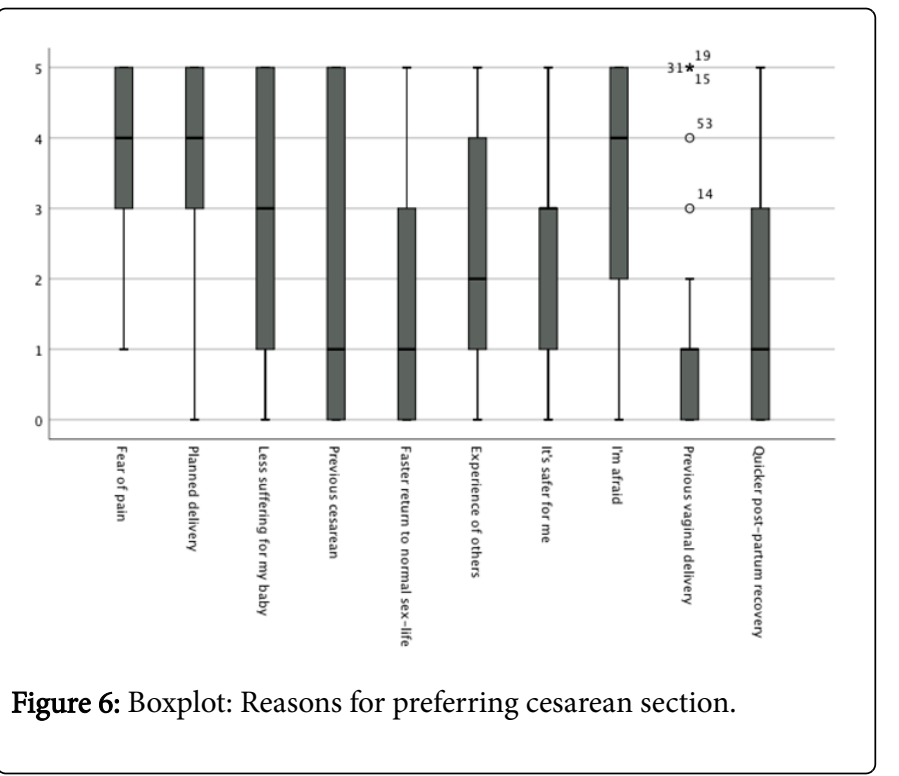

\section{Sources of information}

The answers regarding the sources of information that influenced the pregnant women in their decision making are shown in Table 4. The source which most influenced the preference was the attending physician, followed by relatives, friends and the Internet. Taking into account the Pearson's Chi-square test (Table 4) there is a statistically significant relationship between the preference for the type of delivery and whether or not the information has been obtained by the GP/ obstetrician. The women who indicated their physician as an information source preferred vaginal delivery in $84 \%$ of the cases $(\mathrm{p}<0.05)$ (Table 5).

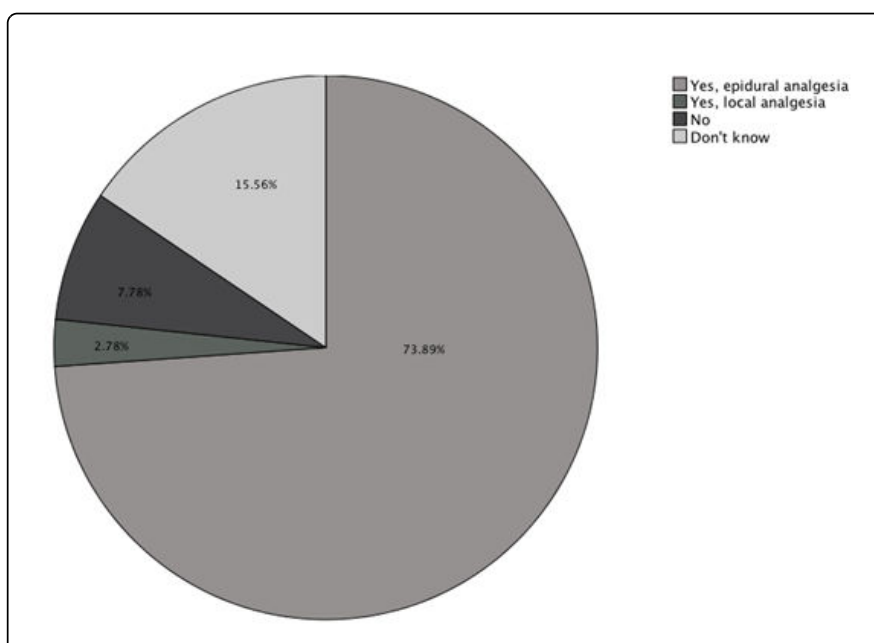

Figure 7: Preference for analgesia in women who prefer vaginal delivery $(\mathrm{n}=180)$. n: number of women.

\section{Discussion}

The aim of the present study was to analyze the delivery mode preference in a representative sample of Portuguese pregnant women.

Only $22 \%$ of Portuguese pregnant women would prefer an elective CS if they could choose. Nevertheless, this number is higher than the $13 \%$ reported by Mazzoni et al. and is twice that of the European average (11\%) [27].

CS preference was shown to be higher in women with previous a CS ( $73 \%$ of women with CS), which is in line with findings by Mazzoni et al. [27]. 
Citation: Costa IC, Nunes CS, Machado HS (2018) Mode of Delivery and Labour Analgesia: A Study of Preference in Portuguese Pregnant Women. J Anesth Clin Res 9: 849. doi:10.4172/2155-6148.1000849

Page 8 of 11
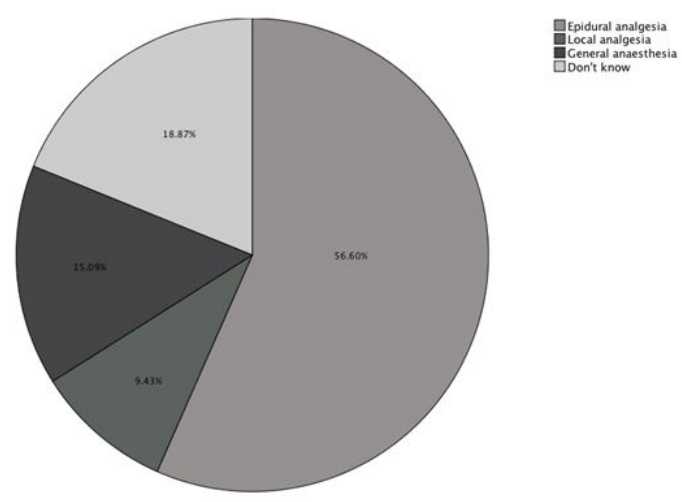

Figure 8: Preference for analgesia in women who prefer cesarean section $(n=53)$. n: number of women.

Preference for vaginal delivery was higher in women with more advanced pregnancies ( 26 weeks compared to 23 weeks in women who preferred cesarean section). The influence of the gestational age on the preferred mode of delivery is not constant between studies. However, the evolution of preference during pregnancy in longitudinal studies has been described, with different results as is the case of Karlström et al. [43] and Moffat et al. [44]. This is relevant because it may have implications at the most appropriate time for advising pregnant women.

\begin{tabular}{|l|l|l|l|l|}
\hline & & $\begin{array}{l}\text { Chose their } \\
\text { physician }\end{array}$ & $\begin{array}{l}\text { Didn't choose } \\
\text { their } \\
\text { physician }\end{array}$ & Total \\
\hline $\begin{array}{l}\text { Preferred mode } \\
\text { of delivery }\end{array}$ & Vaginal $(\mathrm{n})$ & 100 & 90 & \multirow{2}{*}{190} \\
\cline { 2 - 4 } & $\mathrm{n}(\%)$ & $73.00 \%$ & $84.10 \%$ & \\
\cline { 2 - 4 } & Cesarean (n) & 37 & 17 & \multirow{2}{*}{54} \\
\cline { 2 - 4 } & $\mathrm{n}(\%)$ & $27.00 \%$ & $15.9 \%$ & \multirow{2}{*}{244} \\
\hline \multirow{2}{*}{ Total } & & 137 & 107 & \\
\cline { 2 - 4 } & & $56.10 \%$ & $43.90 \%$ & \\
\hline
\end{tabular}

Table 5: Preferred mode of delivery of women that chose their attending physician as a source of information. n: number of women.

\begin{tabular}{|c|c|c|c|c|c|c|c|}
\hline & $\begin{array}{l}\text { Median } \\
\text { IQR }^{1}(75-25)\end{array}$ & $\begin{array}{l}\text { Strongly } \\
\text { disagree }\end{array}$ & Disagree & Neutral & Agree & Strongly agree & $\begin{array}{l}\text { Don't know/Didn't } \\
\text { have }\end{array}$ \\
\hline Doesn't leave scar & $\begin{array}{l}3 \\
5-2=3\end{array}$ & $29(16.7 \%)$ & $18(10.3 \%)$ & $39(22.4 \%)$ & $30(17.2 \%)$ & $53(30.5 \%)$ & $5(2.9 \%)$ \\
\hline $\begin{array}{l}\text { Don't want to lose the first } \\
\text { hour of my babies life }\end{array}$ & $\begin{array}{l}5 \\
5-4=1\end{array}$ & $7(4.0 \%)$ & $4(2.3 \%)$ & $14(8.0 \%)$ & $41(23.4 \%)$ & $107(61.1 \%)$ & $2(1.1 \%)$ \\
\hline I'm afraid & $\begin{array}{l}2 \\
3-1=2\end{array}$ & $48(28.4 \%)$ & $30(17.8 \%)$ & $38(22.5 \%)$ & $15(8.9 \%)$ & $26(15.4 \%)$ & $12(7.1 \%)$ \\
\hline Birth is not surgery & $\begin{array}{l}3 \\
5-1=4\end{array}$ & $40(23.5 \%)$ & $21(12.4 \%)$ & $26(15.3 \%)$ & $23(13.5 \%)$ & $52(30.6 \%)$ & $8(4.7 \%)$ \\
\hline Previous vaginal delivery & $\begin{array}{l}1 \\
5-0=5\end{array}$ & $68(38.6 \%)$ & $1(0.6 \%)$ & $1(0.6 \%)$ & $6(3.4 \%)$ & $52(29.5 \%)$ & $48(27.3 \%)$ \\
\hline Experience of others & $\begin{array}{l}4 \\
5-3=2\end{array}$ & $22(12.7 \%)$ & $7(4.0 \%)$ & $32(18.5 \%)$ & $30(17.3 \%)$ & $75(43.4 \%)$ & $7(4.0 \%)$ \\
\hline $\begin{array}{l}\text { Cesarean can limit } \\
\text { number of children }\end{array}$ & $\begin{array}{l}2 \\
3-1=2\end{array}$ & $49(28.5 \%)$ & $20(11.6 \%)$ & $32(18.6 \%)$ & $8(4.7 \%)$ & $30(17.4 \%)$ & $33(19.2 \%)$ \\
\hline $\begin{array}{l}\text { Quicker post-partum } \\
\text { recovery }\end{array}$ & $\begin{array}{l}5 \\
5-4=1\end{array}$ & $3(1.7 \%)$ & $1(0.6 \%)$ & $18(10.0 \%)$ & $34(18.9 \%)$ & $112(62.2 \%)$ & $12(6.7 \%)$ \\
\hline Shorter hospital stay & $\begin{array}{l}5 \\
5-4=1\end{array}$ & $5(2.9 \%)$ & $3(1.7 \%)$ & $21(12.0 \%)$ & $34(19.4 \%)$ & $98(56.0 \%)$ & $14(8.0 \%)$ \\
\hline Previous cesarean & $\begin{array}{l}1 \\
1-0=1\end{array}$ & $88(52.1 \%)$ & $0(0.0 \%)$ & $1(0.6 \%)$ & $0(0.0 \%)$ & $22(13.0 \%)$ & $58(34.3 \%)$ \\
\hline
\end{tabular}

Table 6: Reasons for preferring vaginal delivery. ${ }^{1}$ Interquartile range.

No significant relationship was found between the level of education and preference for delivery mode. This is contrary to what was found by other studies. However, there is a disparity in findings: some, like Torloni et al. [10] and Loke et al. [45], report that the preference for cesarean section is associated with lower levels of education, whilst others such as Zhang et al. [46], Darsareh et al. [47] and Edwards et al. [48] link this choice to higher educational levels. 
Page 9 of 11

\begin{tabular}{|c|c|c|c|c|c|c|c|}
\hline & Median IQR ${ }^{1}(75-25)$ & $\begin{array}{l}\text { Strongly } \\
\text { disagree }\end{array}$ & Disagree & Neutral & Agree & Strongly agree & Don't know \\
\hline Fear of pain & $\begin{array}{l}4 \\
5-3=2\end{array}$ & $8(15.7 \%)$ & $0(0.0 \%)$ & $12(23.5 \%)$ & $10(19.6 \%)$ & $21(41.2 \%)$ & $0(0.0 \%)$ \\
\hline Planned delivery & $\begin{array}{l}4 \\
5-3=2\end{array}$ & $47.8 \%)$ & $5(9.8 \%)$ & $12(23.5 \%)$ & $9(17.6 \%)$ & $19(37.3 \%)$ & $2(3.9 \%)$ \\
\hline $\begin{array}{l}\text { Less suffering for my } \\
\text { baby }\end{array}$ & $\begin{array}{l}4 \\
5-1=4\end{array}$ & $6(11.8 \%)$ & $1(2.0 \%)$ & $9(17.6 \%)$ & $9(17.6 \%)$ & $17(33.3 \%)$ & $9(17.6 \%)$ \\
\hline Previous cesarean & $\begin{array}{l}1 \\
5-0=5\end{array}$ & $14(26.4 \%)$ & $1(1.9 \%)$ & $1(1.9 \%)$ & $1(1.9 \%)$ & $16(30.2 \%)$ & $20(37.7 \%)$ \\
\hline $\begin{array}{l}\text { Faster return to } \\
\text { normal sex-life }\end{array}$ & $\begin{array}{l}1 \\
3-0=3\end{array}$ & $8(16.0 \%)$ & $5(2.0 \%)$ & $11(4.5 \%)$ & $5(2.0 \%)$ & $3(1.2 \%)$ & $18(36.0 \%)$ \\
\hline Experience of others & $\begin{array}{l}2 \\
4-1=3\end{array}$ & $12(24.0 \%)$ & $8(16.0 \%)$ & $9(18.0 \%)$ & $5(10.0 \%)$ & $9(18.0 \%)$ & $7(14.0 \%)$ \\
\hline Safer & $\begin{array}{l}3 \\
4-1=3\end{array}$ & $5(10.2 \%)$ & $3(6.1 \%)$ & $17(6.9 \%)$ & $4(1.6 \%)$ & $9(3.7 \%)$ & $11(22.4 \%)$ \\
\hline I'm afraid & $\begin{array}{l}4 \\
5-2=3\end{array}$ & $8(8.0 \%)$ & $3(6.0 \%)$ & $9(18.0 \%)$ & $7(14.0 \%)$ & 19 (38.0\%) & $4(8.0 \%)$ \\
\hline $\begin{array}{l}\text { Previous } \\
\text { delivery }\end{array}$ & $\begin{array}{l}1 \\
1-0=1\end{array}$ & $21(43.8 \%)$ & $2(4.2 \%)$ & $1(2.1 \%)$ & $1(2.1 \%)$ & $5(10.4 \%)$ & $18(37.5 \%)$ \\
\hline $\begin{array}{l}\text { Quicker post-partum } \\
\text { recovery }\end{array}$ & $\begin{array}{l}1 \\
3-0=3\end{array}$ & $13(27.7 \%)$ & $8(17.0 \%)$ & $7(14.9 \%)$ & $4(8.5 \%)$ & $1(2.1 \%)$ & $14(29.8 \%)$ \\
\hline
\end{tabular}

Table 7: Reasons for preferring cesarean section. ${ }^{1}$ Interquartile range.

The main reasons that led the participants to prefer a vaginal delivery are reinforced by other studies that also highlight the faster postpartum recovery and shorter hospital stay $[10,49]$ as well as not wanting to lose the first hours of life of their child [10]. These were all statements in which women had similar opinions: most women strongly agreed that these factors were what lead them to prefer a vaginal delivery.

Within the list of ten reasons for cesarean preference, the main reasons cited were fear of pain, fear in general and the possibility of scheduling the childbirth. These were also the statements that presented less dispersion i.e., where most women had similar answers. These findings are in agreement with previous knowledge that fear of childbirth is often a reason leading women to prefer a CS as was also highlighted by Karlström et al. [43] and others [50,51]. The convenience of an elective CS has also been reported by Torloni et al. [10] and others [48,52-55]. Since three women reported in the open response that their preference for cesarean section was health-related (and therefore not a preference, but a necessity), it would have been appropriate to have given respondents the option to indicate if the fact that they chose CS as their preferred mode of delivery was due to a medical indication, so as to better determine the reasons for their choice.

When asked about the type of analgesia preferred, in both groups, most respondents preferred epidural analgesia. The preference for this type of analgesia has been associated with multiparous women, older age and higher levels of education as was reported by Stark [38] and
Wassen et al. [56]. However, the present study did not reveal any statistically significant relationship between preference for the type of analgesia and the other factors that were accessed.

Regarding the way in which the respondents obtained the information that helped them decide their preferences, the most frequently mentioned source of information was their GP or obstetrician (44\%). Pregnant women who indicated their doctor as a source of information were more likely to prefer vaginal delivery, as was found in $84 \%$ of the cases. As the primary health care providers obstetricians and GPs are expected to provide the necessary information to pregnant women regarding different types of delivery. As such, doctor's own preferences and attitudes can influence a woman's preferences. This finding highlights the importance of learning about childbirth through the attending physician.

Because the sample size was determined beforehand and the study was conducted in the largest maternity hospital at national level [40], it was possible to obtain a representative sample of the Portuguese population. In fact, although the number of respondents with previous cesarean sections was higher than the national average (40\% and $32 \%$ [15] respectively), the demographics of the study sample were in accordance with the country's reality. The mean age of the pregnant women included (31.7 years) was close to the national average for maternal age at the birth of a child (31.9 years) [54]. The distribution of the level of education in the sample, according to the most recent data, was comparable to national numbers of maternal education [55]. 
Page 10 of 11

In light of what has been discussed previously, the fact that the study was conducted in a public institution may have introduced a sampling bias, since the percentage of CS in private hospitals is double that of state run hospitals [17]. However, it is known that many women who choose to deliver in private hospitals are followed in the public health system. Nevertheless, this study shows that only a minority of pregnant women express a preference for CS and, despite maternal preference being one of the reasons most frequently mentioned [22-24,36,51] it seems unlikely that this explains the high rates of cesarean section, particularly in private institutions where rates are around 65\% [17].

\section{Conclusions}

In this study, a minority of pregnant women surveyed showed a preference for cesarean section. This preference was higher in women with previous CS. Regardless of preferring CS or vaginal birth, the majority of women would choose to have epidural analgesia. Despite high CS rates nationwide, maternal cesarean desire is low, suggesting that this number is due to factors other than the preference of pregnant women.

\section{References}

1. US National Library of Medicine (2018) Cesarean Section-A Brief History.

2. Liu S, Liston RM, Joseph KS, Heaman M, Sauve R, et al. (2007) Maternal mortality and severe morbidity associated with low-risk planned cesarean delivery versus planned vaginal delivery at term. CMAJ 176: 455-460.

3. Knight M, Kurinczuk JJ, Spark P, Brocklehurst P, United Kingdom Obstetric Surveillance System Steering Committee (2008) Cesarean delivery and peripartum hysterectomy. Obstet Gynecol 111: 97-105.

4. Villar J, Carroli G, Zavaleta N, Donner A, Wojdyla D, et al. (2007) Maternal and neonatal individual risks and benefits associated with caesarean delivery: multicentre prospective study. BMJ 335: 1025.

5. https://www.nice.org.uk/guidance/cg132/evidence.

6. http://apps.who.int/gho/data/node.wrapper.imr?x-id=68.

7. No authors listed (1985) Appropriate technology for birth. Lancet. 2: 436-437.

8. http://apps.who.int/iris/bitstream/handle/10665/161442/ WHO_RHR_15.02_eng.pdf

9. Betrán A, Ye J, Moller AB, Zhang J, Gülmezoglu AM, Torloni MR (2016) The Increasing Trend in Caesarean Section Rates: Global, Regional and National Estimates: 1990-2014. PLoS One 11: e0148343.

10. Torloni MR, Betrán AP, Montilla P, Scolaro E, Seucet A, et al. (2013) Do Italian women prefer cesarean section? Results from a survey on mode of delivery preferences. BMC Pregnancy and Childbirth 13: 78.

11. https://data.oecd.org/healthcare/caesarean-sections.htm.

12. Ye J, Zhang J, Mikolajczyk R, Torloni MR, Gülmezoglu AM, et al. (2016) Association between rates of caesarean section and maternal and neonatal mortality in the 21 st century: a worldwide population-based ecological study with longitudinal data. BJOG 123: 745-753.

13. OECD (2009) Health at a Glance. Paris: OECD Publishing.

14. OECD (2013) Health at a Glance. Paris: OECD Publishing.

15. OECD (2017) Health at a Glance. Paris: OECD Publishing.

16. https://www.pordata.pt.

17. Pordata (2018) Partos nos Hospitais Privados: total e por tipo - Consulta Avançada.

18. Villar J, Valladares E, Wojdyla D, Zavaleta N, Carroli G, et al. (2006) Caesarean rates and pregnancy outcomes: the 2005 WHO global survey on maternal and perinatal health in Latin America. Lancet 367: 1819-1829.
19. Potter JE, Berquó E, Perpétuo IH , Leal OF, Hopkins K, et al. (2011) Unwanted caesarean sections among public and private patients in Brazil: prospective study. BMJ 323: 1155-1158.

20. A Mazzoni, F. Althabe, L Gutierrez (2016) Women's preferences and mode of delivery in public and private hospitals: a prospective cohort study. BMC Pregnancy and Childbirth 16: 34.

21. http://www.spp.pt/UserFiles/file/EVIDENCIAS\%20EM\%20PEDIATRIA/ DGS_001_2015\%2001.2015.pdf

22. Marshall NE, Fu R, Guise J (2011) Impact of multiple caesarean deliveries on maternal morbidly: a systematic review. Am J Obstet Gynecol 205: 262.e1-8

23. Lumbiganon $P$, Laopaiboon $M$, Gülmezoglu AM, Souza JP, Taneepanichskul S (2010) Method of delivery and pregnancy outcomes in Asia: the WHO global survey on maternal and perinatal health. Lancet 375: 490-499.

24. Souza JP, Gülmezoglu A, Lumbiganon P, Laopaiboon M, Carroli G, et al. (2010) Caesarean section without medical indications is associated with an increased risck of adverse short-term maternal outcomes. BMC Med 8: 71.

25. Dobson R (2001) Caesarean section rate in England and Wales hits 21. BMJ 323: 951.

26. Langer A, Villar J (2002) Promoting evidence based practice in maternal care. BMJ 324: 928-929.

27. Mazzoni A, Althabe F, Liu NH, Bonotti AM, Gibbons L, et al. (2011) Women's preference for caesarean section: a systematic review and metaanalysis of observational studies. BJOG 118: 391-399.

28. Högberg U, Lynöe N, Wulff M (2010) Cesarean by choice? Empirical study of public attitudes. Acta Obstet Gynecol Scand 87: 1301-1308.

29. Fuglenes D, Aas E, Botten G, Øian P, Kristiansen IS (2011) Why do some pregnant women prefer cesarean? The influence of parity, delivery experiences, and fear. Am J Obstet Gynecol 205: 45.e1-9.

30. Rivo JC, Amyx M, Pingray V, Casale RA, Fiorillo AE, et al. (2018) Obstetrical providers' preferred mode of delivery and attitude towards nonmedically indicated caesarean sections: a crosssectional study. BJOG.

31. Gonen R, Tamir A, Degani S (2002) Obstetricians' opinion regarding patient choice in cesarean delivery. Obstet Gynecol 99: 577-580.

32. Cotzias CS, Paterson-Brown S, Fisk NM (2001) Obstetricians say yes to maternal request for elective caesarean section: a survey of current opinion. Eur J Obstet Gynecol Reprod Biol 97: 15-16.

33. Bergholt T, Østberg B, Legarth J, Weber T (2004) Danish obstetricians' personal preference and general atitude to elective cesaren on maternal request: a nation-wide postal survey. Acta Obstet Gynecol Scand 83: 262-266.

34. Pang SM, Leung DT, Leung TY, Lai CY, Lau TK, et al. (2007) Determinants of preference for elective caesarean section in Hong Kong Chinese pregnant women. Hong Kong Med 13: 100-105.

35. Labor S, Maguire S (2008) The Pain of Labour. Rev Pain. 2: 15-19.

36. Jones L, Othoman M, Dowswell T, Alfirevic Z, Gates S, et al. (2012) Pain management for women in labour - an overview of systematic reviews. Cochrane Database Syst Rev.

37. Silva M, Halpern SH (2010) Epidural analgesia for labor: Current techniques. Local Reg Anesth 3: 143-153.

38. Stark MA (2003) Exploring Women's Preferences for Labor Epidural Analgesia. J Perinat Educ 12: 16-21.

39. Anim-Somuah M, Smyth RM, Jones L (2011) Epidural versus nonepidural or no analgesia in labour. Cochrane Database Syst Rev 12: CD000331.

40. http://www.chporto.pt/ver.php? $\operatorname{cod}=0 \mathrm{~A} \&$ und $=\mathrm{jd}$

41. http://www.chporto.pt/ver.php? $\operatorname{cod}=0 \mathrm{O} 0 \mathrm{E}$

42. https://www.ine.pt/xportal/xmain?

xpid=INE\&xpgid=ine_indicadores\&indOcorrCod $=0008349 \&$ contexto $=b$ $\mathrm{d} \&$ selTab=tab2 
Citation: Costa IC, Nunes CS, Machado HS (2018) Mode of Delivery and Labour Analgesia: A Study of Preference in Portuguese Pregnant Women. J Anesth Clin Res 9: 849. doi:10.4172/2155-6148.1000849

Page 11 of 11

43. Karlström A, Nystedt A, Johansson M, Hildingsson I (2010) Behind the myth-few women prefer caesarean section in the absence of medical or obstetrical factors. Midwifery 27: 620-627.

44. Moffat MA, Bell JS, Porter MA, Lawton S, Hundley V, et al. (2007) Decision making about mode of delivery among pregnant women who have previously had a caesarean section: A qualitative study. BJOG 114 86-93.

45. Loke AY, Davies L, Li SF (2015) Factors influencing the decision that women make on their mode of birth: the Health Belief Model. BMC Health Serv Res 15: 274.

46. Zhang J, Liu Y, Meikle S, Zheng J, Sun W, et al. (2008) Cesarean Delivery on Maternal Request in Southeast China. Obstet Gynecol 111: 1077-1082.

47. Darsareh F, Aghamolaei T, Rajaei M, Madani A, Zare S (2016) The differences between pregnant women who request elective caesarean and those who plan for vaginal birth based on Health Belief Model. Women Birth 29: e126-e132.

48. Edwards GJ, Davies NJ (2001) Elective caesarean section-the patient's choice? J Obstet Gynaecol 21: 128-129.

49. Silva A, Felix H, Ferreira M (2017) Preference for type of childbirth, factors associated with expectation and satisfaction with childbirth.
50. Waldenström U, Hildingsson I, Ryding EL (2006) Antenatal fear of childbirth and its association with subsequent cesarean section and experience of childbirth. BJOG 113: 638-646.

51. Stoll K, Edmonds JK, Hall WA (2015) Fear of Childbirth and Preference for Cesarean Delivery Among Young American Women Before Childbirth: A Survey Study. Birth 42: 270-276.

52. Fenwick J, Staff L, Gamble J, Creedy DK, Bayes S (2010) Why do women request caesarean section in a normal, healthy first pregnancy? Midwifery 26: 394-400.

53. Minkoff H, Chervenak FA (2003) Elective primary cesarean delivery. N Engl J Med 348: 946-950.

54. Pordata (2018) Idade média da mãe ao nascimento de um filho-Consulta avançada. Base de Dados de Portugal Contemporâneo.

55. Pordata (2018) Nados-vivos de mães residentes em Portugal: total e por nível de escolaridade completo mais elevado da mãe-Consulta avançada.

56. Wassen M, Miggiels L, Devlieger R, Gyselaers W, Mertens H, et al. (2013) Women's prelabour preference for epidural analgesia: a cross-sectional study among women from the Netherlands and Belgium. J Psychosom Obstet Gynaecol 34: 22-28. 